\title{
A Soybean Oil-Based Liposome-Polymer Transfection Complex as a Codelivery System for DNA and Subunit Vaccines
}

\author{
Yu-Ling Lin, ${ }^{1}$ Li-Yi Chen, ${ }^{2}$ Chia-Hung Chen, ${ }^{1}$ Yen-Ku Liu, ${ }^{1}$ Wei-Tung Hsu, ${ }^{1}$ \\ Li-Ping Ho, ${ }^{2}$ and Kuang-Wen Liao ${ }^{1,3}$ \\ ${ }^{1}$ Institute of Molecular Medicine and Bioengineering, National Chiao Tung University, Hsinchu 30068, Taiwan \\ ${ }^{2}$ Institute of Biological Science and Technology, National Chiao Tung University, Hsinchu 30050, Taiwan \\ ${ }^{3}$ Department of Biological Science and Technology, National Chiao Tung University, No.75 Po-Ai Street, Hsinchu 30068, Taiwan
}

Correspondence should be addressed to Kuang-Wen Liao, lyring@pchome.com.tw

Received 25 June 2011; Revised 20 September 2011; Accepted 9 November 2011

Academic Editor: Jun Li

Copyright (c) 2012 Yu-Ling Lin et al. This is an open access article distributed under the Creative Commons Attribution License, which permits unrestricted use, distribution, and reproduction in any medium, provided the original work is properly cited.

\begin{abstract}
Inexpensive liposome-polymer transfection complexes (LPTCs) were developed and used as for DNA or protein delivery. The particle sizes of the LPTCs were in the range of 212.2 to $312.1 \mathrm{~nm}$, and the zetapotential was $+38.7 \mathrm{mV}$. LPTCs condensed DNA and protected DNA from DNase I digestion and efficiently delivered LPTC/DNA complexes in Balb/3T3 cells. LPTCs also enhanced the cellular uptake of antigen in mouse macrophage cells and stimulated TNF- $\alpha$ release in naïve mice splenocytes, both indicating the potential of LPTCs as adjuvants for vaccines. In vivo studies were performed using $H$. pylori relative heat shock protein 60 as an antigen model. The vaccination of BALB/c mice with LPTC-complexed DNA and protein enhanced the humoral immune response. Therefore, we developed a DNA and protein delivery system using LPTCs that is inexpensive, and we successfully applied it to the development of a DNA and subunit vaccine.
\end{abstract}

\section{Introduction}

Most vaccines have been developed using live attenuated organisms, killed whole organisms, or inactivated toxins. Live vaccines are intrinsically unstable and have a serious risk of reverting back to their virulent state, and, thus, they are difficult to use. Furthermore, because the whole organisms are killed or inactivated, these vaccines generate a weaker immune response and typically require multiple doses. Thus, recent efforts have focused on utilizing technologies such as recombinant DNA to develop DNA and subunit vaccines [1, $2]$. Theses vaccines are attractive because of their increased safety since they cannot revert to a virulent form and they lack contaminants from the original pathogenic organism. Additionally, the ability to consistently produce large, welldefined quantities of antigen from recombinant methods is highly desirable.

A DNA vaccine is an antigen-encoding plasmid that upon introduction into the body is capable of directing in vivo expression of that protein. This can induce antigen-specific immune responses. DNA vaccines are able to induce cellular immune responses (cell-mediated immunity) in addition to antibody responses (humoral immunity). Generally, cellular immunity is better able to fight viruses and parasites. DNA plasmid vectors carry the genetic information encoding an antigen, and, thus, the antigen can be produced inside the host cell. The DNA vaccine-derived protein antigen is then degraded by proteosomes into intracellular peptides and is bound to MHC class I molecules on the cell surface. The peptide antigen/MHC complexes bind to cytotoxic $\mathrm{CD} 8^{+}$ lymphocytes and induce a cell-mediated immune response. DNA vaccines can be designed to express the associated protein from infectious bacteria or viruses that is recognized by the immune system. DNA vaccines are able to induce the expression of antigens that resemble the natural epitopes more closely than standard vaccines. DNA vaccination could trigger both cellular and humoral immune responses after the internal production and presentation of the protein. Furthermore, rapid and large-scale production is considerably less expensive than traditional vaccines. They are also stable for storage and transportation much easier. 
Subunit vaccines use only parts of an organism to stimulate a strong immune response. To create a subunit vaccine, the gene that codes for appropriate subunits from the genome of the infectious agent are placed into bacteria or yeast host cells to produce large quantities of subunit molecules. These foreign molecules can be isolated, purified from host cells and used as a vaccine. Hepatitis B vaccine is an example of this type of vaccine. With the development of these new types of vaccines, there is a critical need for additional delivery vehicles as well as new adjuvants.

Several nanoparticles have been used for gene delivery, immuneregulation, specific targeting, or detection [3]. Cationic liposomes have been used extensively in both gene therapy and vaccine research. This is based on the idea that cationic liposomes are able to deliver the antigen to the antigen-presenting cells (APCs) and thus enhance antigenspecific immune responses. Moreover, cationic liposomes are much more potent than anionic or neutral liposomes for generating a cell-mediated immune response [4], as the adsorption of antigen onto the cationic liposome increases the efficiency of antigen presentation. Adsorption has been suggested to be the primary adjuvant mechanism of cationic liposomes, by which targeting the cell membrane of antigenpresenting cells subsequently leads to enhanced uptake and presentation of antigen [5]. A preclinical study in mice evaluated the effect of liposome formulation on the type of immune response generated for a MUC1 therapeutic cancer vaccine. The results revealed that liposome-associated (either encapsulated or surface-exposed MUC1 peptide BP25) produced a strong specific CTL response [6]. In addition, cationic lipids such as DC-Chol and DDA have been effectively used as adjuvants to overcome the observed nonresponsiveness to the hepatitis B vaccine [7]. Although liposomes constitute one of most studied antigen delivery systems, studies are still underway to enhance their effectiveness. The synergistic effect of liposomal coentrapment of DNA and protein has been shown to exceed the well-known adjuvant effects of plasmid DNA and liposomes. This new approach to vaccination has been termed "codelivery", and it involves the simultaneous presentation of antigen via MHC class-I (DNA) and MHC class-II (protein) pathways to $\mathrm{CD} 8^{+}$and $\mathrm{CD}^{+}$cells that commonly occurs with live viral pathogens.

In this study, we evaluated novel liposome-polymer transfection complexes as a delivery system and applied the system in the development of a DNA and subunit protein antigen vaccine. The delivery system is easy to manufacture and low in cost compared with general cationic liposome antigen delivery systems. Thus, we demonstrate the potential to apply this system in the development of animal vaccines for farm animals that need large quantities of vaccines with low cost, particularly for species where a large number of animals with a relatively low commercial value are utilized, such as chickens.

\section{Experimental Methods}

2.1. Chemicals. PEI (branched form, average molecular weight of $25 \mathrm{kDa}$ ) was purchased from Aldrich Chemical Co. (St. Louis, MO, USA). PEG (average molecular weight of
$8,000 \mathrm{kDa}$ ) and propidium iodide (PI) were purchased from Sigma Co. (St. Louis, MO, USA). Soybean oil was purchased from Uni-President Co. (Taiwan, ROC). Fetal bovine serum (FBS), Dulbecco's modified Eagle's medium (DMEM), RPMI-1640 medium, antibiotics (penicillin $100 \mathrm{U} / \mathrm{mL}$; streptomycin $100 \mu \mathrm{g} / \mathrm{mL}$ ), SYBR green, and trypan blue stain were purchased from GIBCO (Grand Island, NY, USA).

2.2. Cell Culture and Plasmids. The mouse embryo fibroblast cell line Balb/3T3 was cultured in DMEM with 10\% FBS and $1 \%$ PSA. The mouse lymphoblast cell line P338/D1 was cultured in RPMI with 10\% FBS and 1\% PSA. Cells were cultured in a $37^{\circ} \mathrm{C}$ incubator with $5 \% \mathrm{CO}_{2}$. The plasmid pAAV-MCS-hrGFP was from Dr. Liao's Lab (Department of Biological Science and Technology, NCTU).

2.3. Mice and Immunogens. Female BALB/cByJNarI mice of 3-5 weeks of age were purchased from the National Laboratory Animal Center (NLAC). All mice were maintained under standard pathogen-free conditions. Female mice were used at 9-10 weeks of age. For the DNA vaccine, the pCJ3HpHsp60 plasmid was a gift from Dr. Wu's Lab (Department of Food Science, NTOU). Plasmid DNA was purified by anion exchange chromatography (Qiagen-tip 2500 Mega Prep Kit, Qiagen, Germany). For the subunit protein vaccine, recombinant $H$. pylori heat-shock protein 60 ( $\mathrm{rHpHsp60)}$ was encoded by pET 30a-HpHsp60 DNA, which was from Dr. Liao's Lab (Department of Biological Science and Technology, NCTU).

\subsection{Preparation of Liposome-Polymer Transfection Complexes.} Liposome-polymer transfection complexes (LPTCs) were formed by two hydrophilic polymers (PEI, PEG) and soybean oil; the two phases were mixed by sonication. Briefly, the first step was to make separate oil and aqueous phases. In the aqueous phase, polyethyleneimine (PEI) and polyethylene glycol (PEG) at a 1:1 molar ratio were dissolved in $\mathrm{ddH}_{2} \mathrm{O}$. After the aqueous phase was prepared, $10 \%$ of the total volume soybean oil was added to the aqueous phase. Then, the mixture was vortexed for $10 \mathrm{~min}$ and sonicated at $25 \mathrm{~W}$ for $30 \mathrm{~min}$ at room temperature until it formed a milky white appearance; the mixture was stored at $4^{\circ} \mathrm{C}$.

2.5. Transmission Electron Microscopy (TEM). The mixture was placed onto a 400 mesh copper grid coated with carbon. About 2 min after deposition, the grid was tapped with filter paper to remove surface water and placed into a dry box for two days.

2.6. Particle Size and Zetapotential Measurement. The particle size and zetapotential of the LPTCs were measured by the laser light scattering method using a Malvern Zetasizer $3000 \mathrm{HS}$ (Malvern Instruments, UK). Here, we used the ratio of the moles of amine groups of PEI to those of the phosphate groups of DNA $(N / P)$ to describe the PEI/DNA complexes (PEI contained in LPTCs). The LPTC/DNA binary complexes were prepared at $N / P$ ratios ranging from 1 to 30 containing $50 \mu \mathrm{g}$ of DNA. Then, the prepared complexes were 
incubated for $30 \mathrm{~min}$ and diluted by distilled water to $1 \mathrm{~mL}$ volume for the size and zetapotential measurements. The distribution of particle sizes was measured by dynamic light scattering (90 plus, Brookhaven Instruments Corp., USA).

2.7. Gel Electrophoresis Assay. The LPTC/DNA binary complexes at varying $N / P$ ratios ranging from 1 to 30 were prepared by adding appropriate volumes of LPTC to $300 \mathrm{ng}$ of plasmid DNA prestained by $1 \mu \mathrm{L}$ of SYBR Green in $\mathrm{ddH}_{2} \mathrm{O}$. The binary complexes were incubated at $37^{\circ} \mathrm{C}$ for $30 \mathrm{~min}$, and then heparin (Sigma, St. Louis, MO) was added at different dosages from $150 \mu \mathrm{g}$ to $1 \mu \mathrm{g}$. After $10 \mathrm{~min}$, the complexes in a total volume of $10 \mu \mathrm{L}$ were loaded on the $0.8 \%$ $(\mathrm{w} / \mathrm{v})$ agarose gel with Tris-acetate (TAE) running buffer at $100 \mathrm{~V}$ for $30 \mathrm{~min}$. DNA was visualized with a UV lamp using the Uni-photo gel image system (EZ lab, Taiwan, ROC).

2.8. DNase I Protection Assay. The LPTCs were complexed with $300 \mathrm{ng}$ DNA at an N/P ratio of 10 , and then the complexes were treated with the following: (1) DNase I alone (1 unit), (2) DNase I and heparin at the same time, (3) DNase I then heparin, or (4) heparin alone. For the treatment of DNAase I, $300 \mathrm{ng}$ of DNA was incubated with 1 unit of DNase I in a $20 \mu \mathrm{L}$ reaction mixture at $37^{\circ} \mathrm{C}$ for $30 \mathrm{~min}$, and then $0.5 \mathrm{M}$ EDTA was used to stop the reaction, followed by the addition of heparin or buffer. The DNA complexes were analyzed by $0.8 \%$ agarose gel electrophoresis.

2.9. Cytoxicity of LPTC. Balb/3T3 cells were seeded into 96well culture plates at $2 \times 10^{4}$ cells $/ 100 \mu \mathrm{L} /$ well. Ten $\mu \mathrm{L}$ LPTC with different concentrations were added into each well and incubated for $72 \mathrm{~h}$ in $\mathrm{CO}_{2}$ incubator at $37^{\circ} \mathrm{C}$. Then, the cell viability was determined by stander procedural for MTT assay. The percent relative activity was calculated by $\left(A_{1} / A_{0}\right) \times 100 \%$, in which $A_{1}$ is the absorbances of treated samples and $A_{0}$ is the absorbances of untreated samples.

2.10. In Vitro Transfection Assay. Cells were seeded in 6well plates at a density of $2.5 \times 10^{5}$ cells/well and cultured with $2 \mathrm{~mL}$ of growth medium for 24 hours. Cells were transfected with plasmid DNA encoding the GFP gene by LPTC at various $N / P$ ratios. Briefly, $3 \mu \mathrm{g}$ of plasmid DNA and $5 \mu \mathrm{L}$ of LPTC in different concentrations were each diluted into $100 \mu \mathrm{L}$ of $150 \mathrm{mM} \mathrm{NaCl}$ and vortexed. The LPTC solution was added into the DNA solution for 5 minutes (note the order) and then vortexed. After 20 minutes, the cells were rinsed and supplemented with $200 \mu \mathrm{L}$ of OptiMEM I medium (Gibco, Grand Island, NY). The LPTC/DNA mixture was gently and equally added to each well. Finally, Opti-MEM I medium (600 $\mu \mathrm{L}$, Gibco, Grand Island, NY) was added to each well. After 12 hours incubation, $2 \mathrm{~mL}$ of fresh growth medium was added into each well. After 48 hours, gene expression was measured by FACScan flow cytometry (Becton Dickinson, Mountain View, CA).

2.11. Measurement of Transfection Efficiency by Flow Cytometry. Forty-eight hours after transfection, cells were harvested to measure gene expression. Briefly, the medium was discarded, and each well was rinsed with $1 \mathrm{~mL}$ of PBS. Trypsin
$(1 \mathrm{~mL})$ was then added, and the cells were incubated at $37^{\circ} \mathrm{C}$ for 5 minutes. PBS $(1 \mathrm{~mL})$ was added into each well, and the cells were recovered by centrifugation at $1,500 \mathrm{rpm}$ for 5 minutes at $4^{\circ} \mathrm{C}$. The supernatant was discarded, and the pellet was resuspended in $1 \mathrm{~mL}$ of PBS in FACS tubes. The reporter gene expression was measured by FACScan flow cytometry (Becton Dickinson, Mountain View, CA). Fluorescence intensities were analyzed with CELLQUEST software (Becton Dickinson).

2.12. In Vitro Cellular Uptake Assay. BSA-FITC $(14 \mu \mathrm{g} / \mathrm{mL})$ was mixed with the LPTCs $(4.8 \mu \mathrm{g})$ for $30 \mathrm{~min}$ at room temperature in the dark. P338/D1 cells $\left(2 \times 10^{6}\right.$ cells $\left./ \mathrm{mL}\right)$ were pulsed with BSA-FITC/LPTC complexes and BSA-FITC alone in a humidified atmosphere of $5 \% \mathrm{CO}_{2}$ at $37^{\circ} \mathrm{C}$ or $4^{\circ} \mathrm{C}$. After incubation for $2 \mathrm{~h}$, cells were centrifuged at $4,000 \mathrm{rpm}$ for $5 \mathrm{~min}$ and washed with $1 \mathrm{~mL}$ of cold PBS twice. After the final wash, the supernatant was discarded, and the pellet was resuspended in $1 \mathrm{~mL}$ of cold PBS in FACS tubes. To remove the surface-associated BSA-FITC on the cell membrane, $20 \mu \mathrm{L}$ of trypan blue was added and kept in the dark on ice for an analysis by FACScan flow cytometry (Becton Dickinson, Mountain View, CA).

2.13. Ex Vivo Splenocyte Stimulation of LPTCs. Spleens were isolated aseptically in a laminar flow hood. Organs were cut in several pieces, and clumps were further dispersed by drawing and expelling the suspension several times through a sterile syringe with a $19-G$ needle. Suspensions were filtered through sterile gauzes. After 5 min centrifugation at $1500 \mathrm{rpm}$, pellets were resuspended with $10 \mathrm{~mL}$ of ACK lysis buffer (1x) in DDW and incubated for $10 \mathrm{~min}$. Suspensions were centrifuged at $1500 \mathrm{rpm}$ for $10 \mathrm{~min}$, and then the pellets were washed with $5 \mathrm{~mL}$ of PBS and centrifuged (1500 rpm, $5 \mathrm{~min}$ ) to remove the supernatant. Cells were resuspended with RPMI-1640 medium and immediately used. Splenocytes were seeded in 24 wells at a density of $4 \times 10^{6}$ cells/well, and then $80 \mu \mathrm{g}$ of LPTC was added to cells. Cells were further cultured with $1 \mathrm{~mL}$ of RPMI-1640 medium for $48 \mathrm{hr}$.

2.14. Cytokine Release from Splenocytes. TNF-alpha in cellculture supernatants was collected by centrifugation and assayed by ELISA using the mouse TNF-alpha ELISA development kit (R\&D). The concentration of TNF-alpha was determined using a standard curve. ELISA was performed according to the manufacturer's instructions.

2.15. In Vivo Immunization Regimen. For the heterologous immunization protocol, naïve mice were prime immunized with DNA (pCJ3-HpHsp60) and were boosted with protein (rHpHsp60) (Figure 5(a)). A control group received sterile normal saline solution. DNA was administered at $12.5 \mu \mathrm{g} /$ dose formulated with or without $10 \mu \mathrm{L}$ of LPTC $(3.28 \mathrm{mg} / \mathrm{mL})$ in $5 \%$ glucose PBS, and then protein was administered at $100 \mu \mathrm{g} /$ dose formulated with or without $10 \mu \mathrm{L}$ of LPTC $(100 \mathrm{mg} / \mathrm{mL})$ in $5 \%$ glucose PBS by subcutaneous inoculation. One additional group received $25 \mu \mathrm{g}$ of DNA formulated with $20 \mu \mathrm{L}$ of LPTC $(3.28 \mathrm{mg} / \mathrm{mL})$ in $5 \%$ 

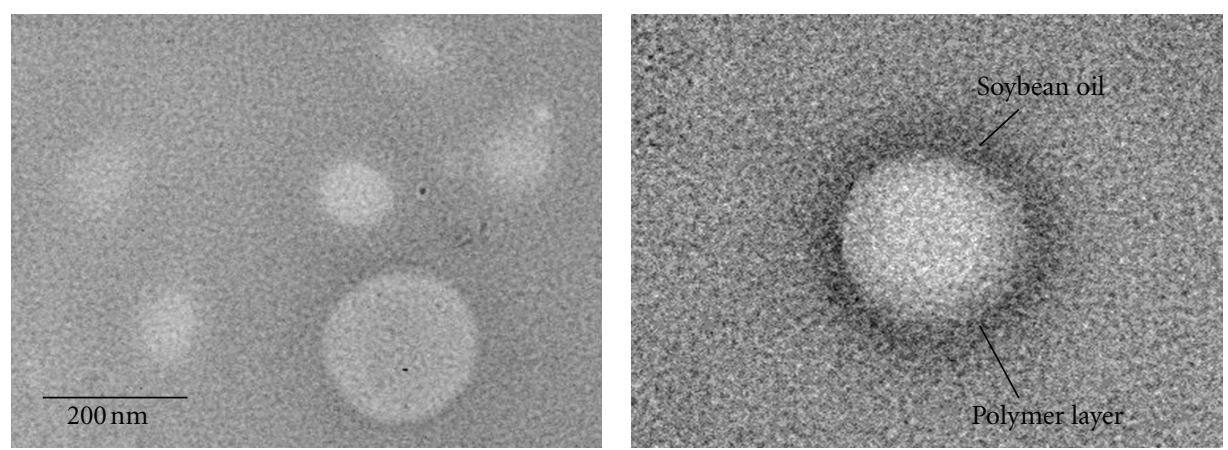

(a)

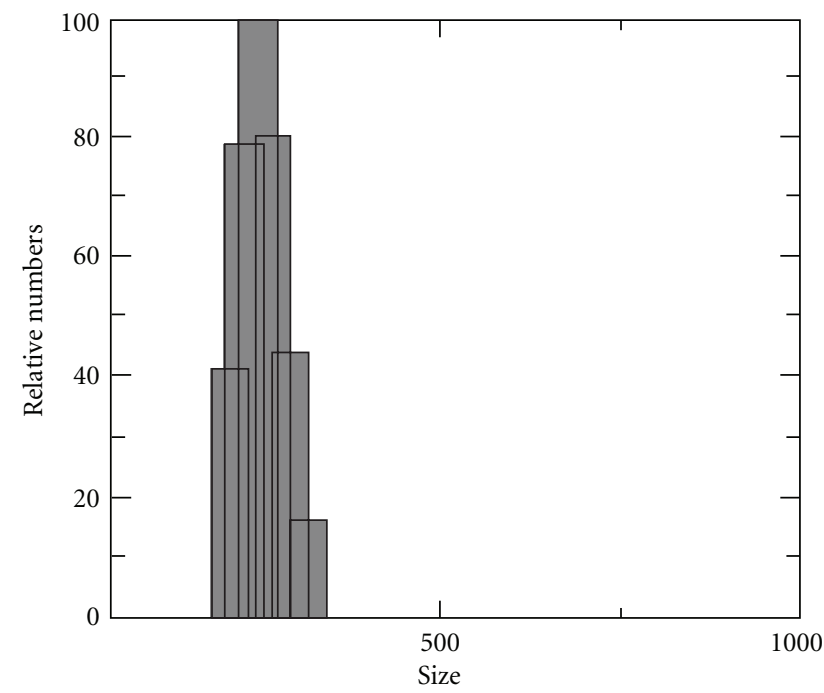

(b)
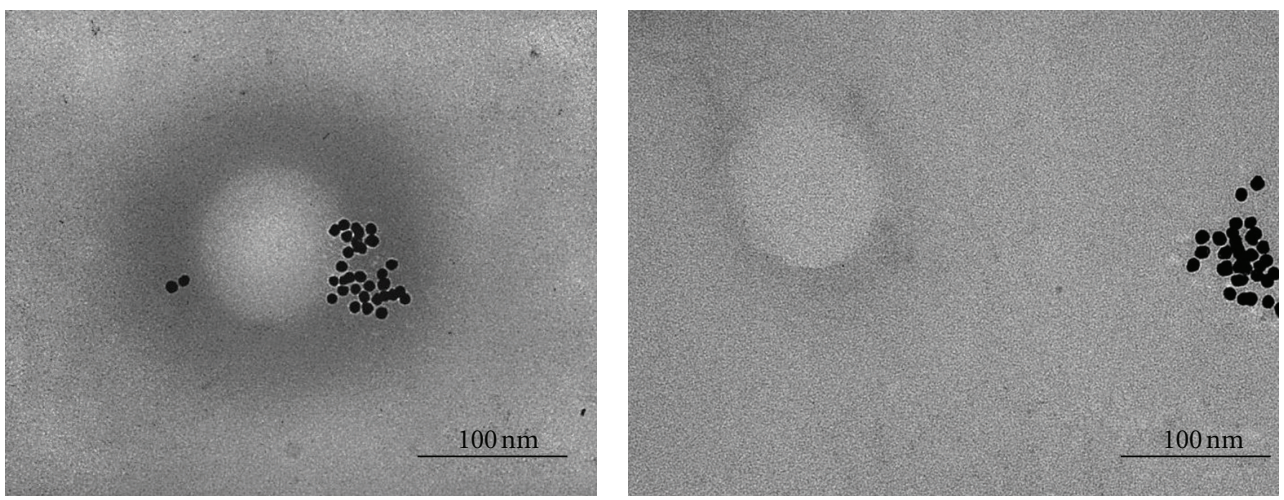

(c)

FIGURE 1: Characteristics of the liposome-polymer transfection complexes (LPTCs). (a) TEM images of LPTC particles. In the left panel, LPTC particles show a round shape and particle sizes ranging from $100 \mathrm{~nm}$ to $300 \mathrm{~nm}$. At high magnification (right panel), the arrow points to the hair-like filaments that are on the outer surface of the LPTC. (b) The particle distribution of LPTCs. The $Y$ axis indicates the relative numbers of particles, and the $X$ axis indicates the diameter $(\mathrm{nm})$ of particles. (c) Images of protein-LPPC complexes. The TEM images showed the BSA-modified gold particles with LPPC or liposomes without polymers.

glucose PBS and boosted by $100 \mu \mathrm{g}$ of protein formulated with $10 \mu \mathrm{L}$ of LPTC $(100 \mathrm{mg} / \mathrm{mL})$ in $5 \%$ glucose PBS. Each mouse was inoculated with $100 \mu \mathrm{L}$ of the formulation.

For the DNA and protein antigen codelivery immunization protocol, we subcutaneously injected $100 \mu \mathrm{g}$ of protein antigen ( $\mathrm{rHpHsp60)}$ and $50 \mu \mathrm{g}$ of DNA (pCJ3-Hphsp60) in
$5 \%$ glucose PBS or $10 \mu \mathrm{L}$ of LPTC $(25 \mathrm{mg} / \mathrm{mL})$ in $5 \%$ glucose PBS buffer (Figure 6(a)). The control group received a sterile normal saline solution. Each mouse was inoculated with $100 \mu \mathrm{L}$ of the formulation. Mice were immunized at 0 and 2 weeks. Blood was collected before each immunization and 2 weeks after the last dose. 


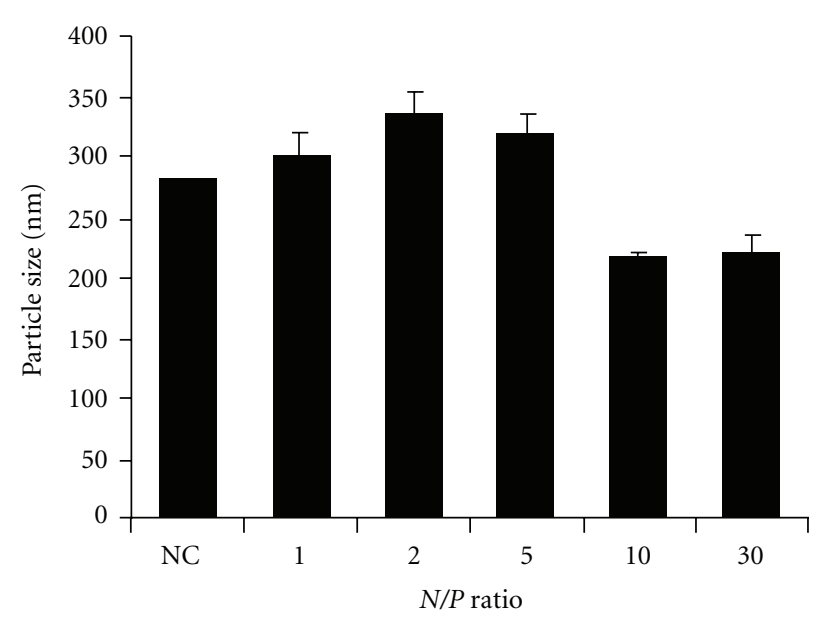

(a)

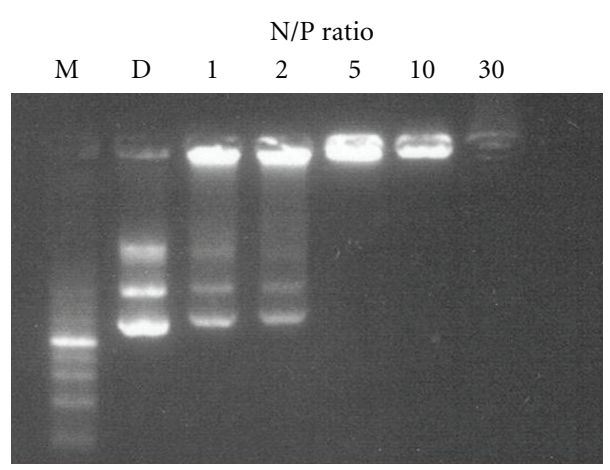

(c)

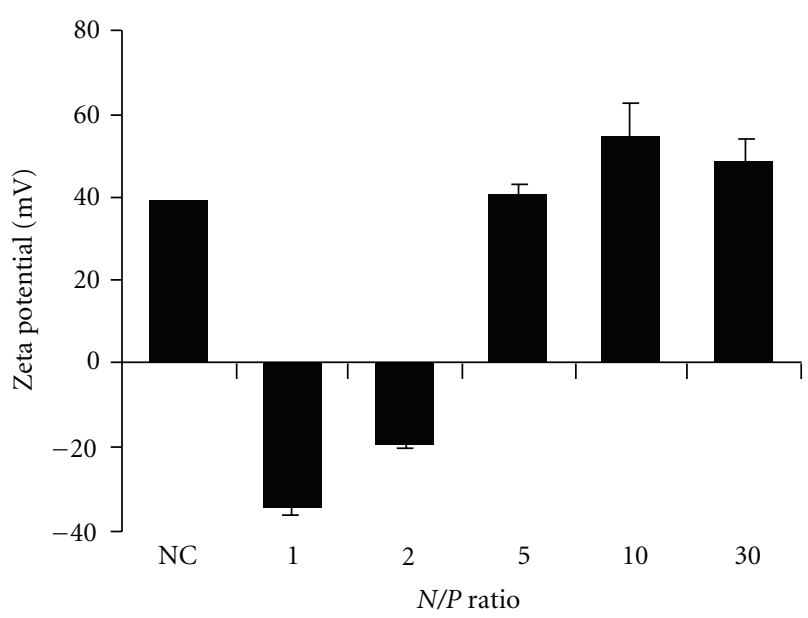

(b)

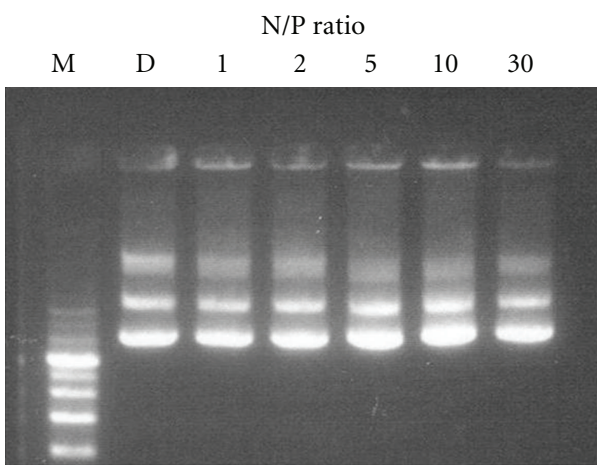

(d)

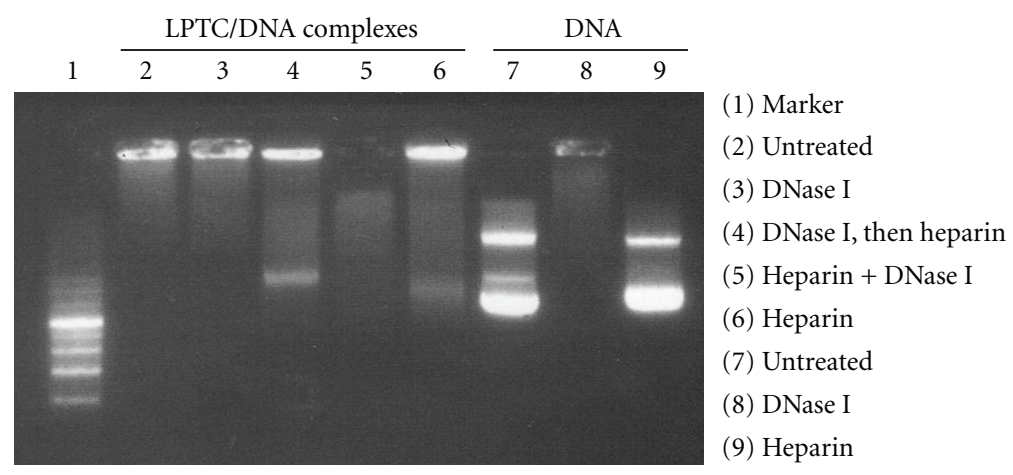

(e)

FIGURE 2: Gel retardation assay of LPTC/DNA complexes. (a) Particle size. (b) zetapotential of LPTC/DNA complexes. Different dosages of LPTC were mixed with $50 \mu \mathrm{g}$ of DNA at different N/P ratios of 1 to 30 . After DNA was incubated with LPTC for 30 min, the particle size and zeta-potential were measured by a Zetasizer. NC indicates the LPTC alone. (c) LPTC at different concentrations was incubated with a fixed amount of DNA for $30 \mathrm{~min}$ at room temperature, and the complexes were run on an agarose gel. Lane 1 is the DNA marker, lane 2 is the naked DNA, and lanes 3 to 7 are complexes at $N / P$ ratios from 1, 2, 5, 10, and 30, respectively. (d) The displacement of DNA from complexes by heparin competition. DNA complexes were treated and analyzed by $0.8 \%$ agarose gel electrophoresis. (e) LPTC protects DNA from DNase I digestion. LPTC protection of DNA from DNase I digestion was assessed by treatment with DNase I, DNase I and heparin, DNase I then heparin, or heparin alone. LPTC/DNA complexes were formed at $N / P=10$ with $300 \mathrm{ng}$ of DNA.

2.16. Determination of Serum Antibody Levels. Blood samples were collected from the retroorbital plexus of mice. Serum anti-HpHsp60-specific antibodies were measured by enzyme-linked immunosorbent assay (ELISA). Briefly, microELISA plates (Nunc-Maxisorp, Nunc, Wiesbaden, Germany) were coated with $100 \mathrm{ng}$ of $\mathrm{rHpHsp60}$ per well in $100 \mu \mathrm{L}$ of
PBS. Serial dilutions of the sera in PBS were added to the antigen-coated wells and then incubated for $1 \mathrm{~h}$ at room temperature followed by three washes with PBS supplemented with $0.05 \%$ Tween 20 . Bound serum antibodies were detected using horseradish peroxidase-conjugated anti-mouse total Ig antibodies at a dilution of 1:5000 followed by incubation 


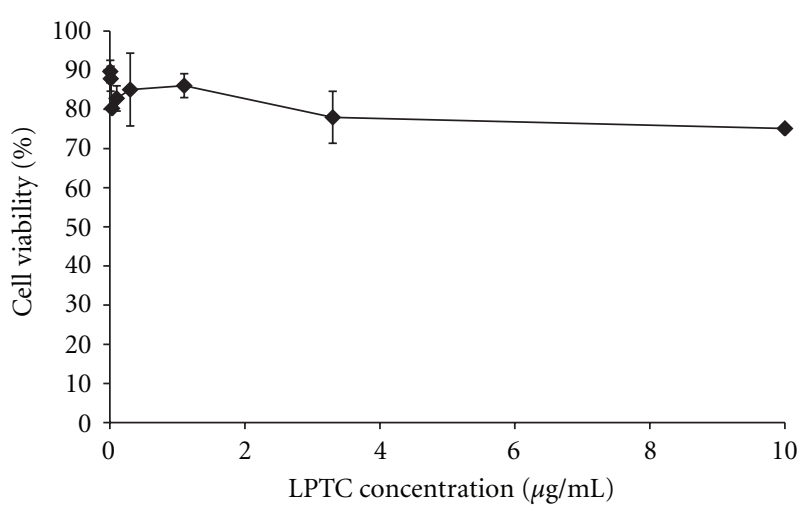

FIGURE 3: The cytotoxicity of LPTC. Balb/3T3 cells were incubated with various dosages of LPTC, and cell viability was measured at $72 \mathrm{~h}$ after treatment. Data represent the percentage to untreated cell.

with TMB. The reaction was stopped by $1 \mathrm{~N} \mathrm{HCl}$, and the extinction was determined at $450 \mathrm{~nm}$. End-point titers were defined as the highest serum dilution that resulted in an absorbance value three times greater than that of negative control sera (derived from nonimmunized mice).

2.17. Statistical Analysis. The results were expressed as mean \pm SE. Statistical significance of differences between mean values was estimated using Student's $t$-test (Microsoft Excel). $P<0.05$ was considered significant.

\section{Results}

3.1. Characterization of Liposome-Polymer Transfection Complexes. The liposome-polymer transfection complexes (LPTCs) were constructed from two hydrophilic polymers (PEG, PEI) and soybean oil. The structure of the LPTCs was also observed by TEM, which showed hollow structure and round shape (Figure 1(a)). Furthermore, the outer surface of the particles was highly dense, similar to a hair-like structure (Figure 1(a) right panel). The hair-like structure is likely the polymers. The sizes of LPTCs were measured by dynamic light scattering (DLS), and the results showed that the particle sizes were distributed between $212.2 \mathrm{~nm}$ and $320.1 \mathrm{~nm}$ (Figure 1(b)). The surface charge of the particles showed cationic properties, and the strength was $+38.6 \mathrm{mV}$ as measured by a Zetasizer. To illustrate the binding sites of protein in the particle, BSA-conjugated gold particles were used as markers. Figure 1(c) showed that BSA-gold particles were located on surface of LPTC using TEM but not on liposomes without polymers. This indicates that the proteins might be bound through polymers and that the binding occurs on the surface of the LPTC particle.

3.2. Gel Retardation of LPTC/DNA Complexes. The cationic LPTC may bind to anionic DNA via electrostatic interaction. Thus, different amounts of LPTC were added to $50 \mathrm{mg}$ of DNA to observe the changes on particle size and zetapotential. As the amounts of LPTC were increased, the sizes of LPTC/DNA complexes increased in N/P ratio from 1 to 5, in contrast to a higher $N / P$ ratio (10 and 30) that decreased their sizes (Figure 2(a)). In addition to the changes in zetapotentials (surface charge), the surface charges decreased from an $N / P$ ratio of 1 to 5 and then increased from 10 to 30 (Figure 2(b)).

The binding capability of DNA is essential for gene transfer. Hence, the DNA binding ability of the LPTCs was examined by agarose gel electrophoresis with different $N / P$ ratios (Figure $2(\mathrm{c})$ ). The result showed that at $N / P$ ratios higher than 5, there was no band on the gel. This result suggests that the plasmid DNA was adsorbed by the LPTC. Heparin was also used to compete with the electrostatic interaction of DNA and LPTC (Figure 2(d)). However, when the complexes were incubated with higher doses of heparin, the migration of DNA was observed at N/P ratios of 1 to 30. Therefore, the results indicated that DNA did bind to the LPTCs.

We next investigated whether DNA complexed to LPTCs is protected from DNase I digestion. To this end, LPTC/DNA complexes were treated with DNase I, and we examined the integrity of DNA bound on LPTCs (Figure 2(e)). Gel electrophoresis revealed that DNA alone without LPTC adsorption was completely degraded by DNase I but not affected by heparin treatment (lanes 7 and 8). In contrast, LPTC/DNA complexes treated with DNase I (lane 2) showed the same intensity as untreated LPTC/DNA complexes (lane 1). In addition, heparin was added to release bound DNA from LPTCs with or without DNase I treatment (lane 3 and 5), and these results showed that DNA bound to LPTCs was not affected by DNase I. By contrast, the bound DNA released from LPTCs by heparin was digested by DNase I (lane 4). Therefore, we concluded that LPTCs have the ability to protect bound DNA from nuclease digestion.

3.3. The Cytoxicity of LPTC. To use the LPTC for application, the cytoxicity of LPTCs were measured. Figure 3 showed that LPTC did not have cytotoxic effects on cells at the dosage which was equivalent to practical application.

3.4. In Vitro Transfection Efficiency of LPTC/DNA Complexes. To in vitro test transfection, LPTCs were complexed with the plasmid DNA pAAV-MCS-hrGFP encoding green fluorescent protein as a reporter gene and added to Balb/3T3 cells in the absence of serum. The transfection efficiency of PEI and lipofectamine 2000 was about $5.3 \%$ and $93.6 \%$. The reporter gene expression was low, $2 \%$ or $13 \%$ at $N / P$ ratios 1 or 5 , in contrast to high efficiency of $32 \%$ or $63 \%$ at ratios 10 or 30 (Figure 4(a)). However, the green fluorescent protein expression was also observed, and the results showed that $N / P$ ratios of 5 and 10 conferred high expression (Figures 4(b) and 4(c)). These results indicate that the N/P ratio of LPTCs affects the transfection efficiency.

3.5. Immune Response to LPTC/BSA-FITC Complexes. Naïve mice splenocytes were extracted and treated with LPTC for $48 \mathrm{~h}$, and then TNF- $\alpha$ secretion was detected in supernatants by cytokine ELISA. The results showed that LPTCs stimulated TNF- $\alpha$ secretion in splenocytes, with higher concentrations of TNF- $\alpha$ secretion $(105 \mathrm{pg} / \mathrm{mL})$ than the control group (26 pg/mL) (Figure 5(a)). 


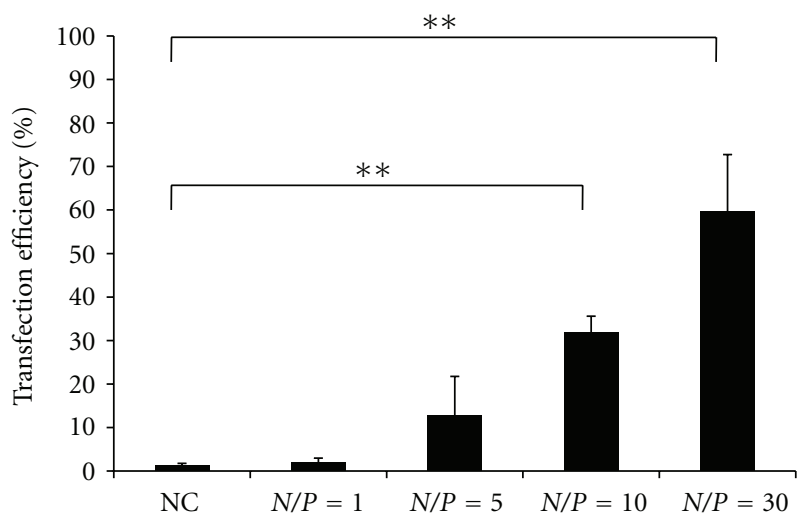

(a)

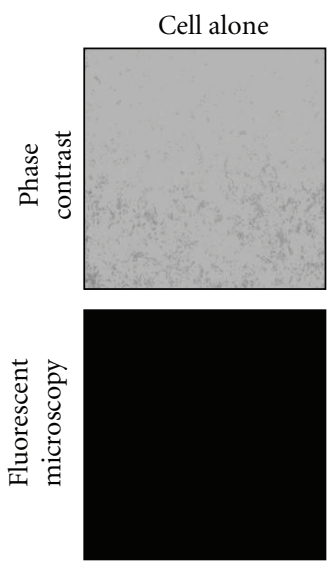

$N / P=1$

$N / P=5$

$N / P=10$
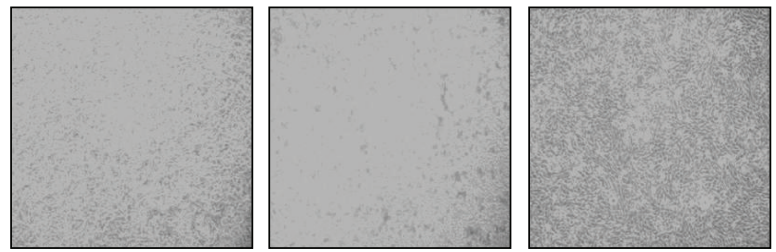

$N / P=30$
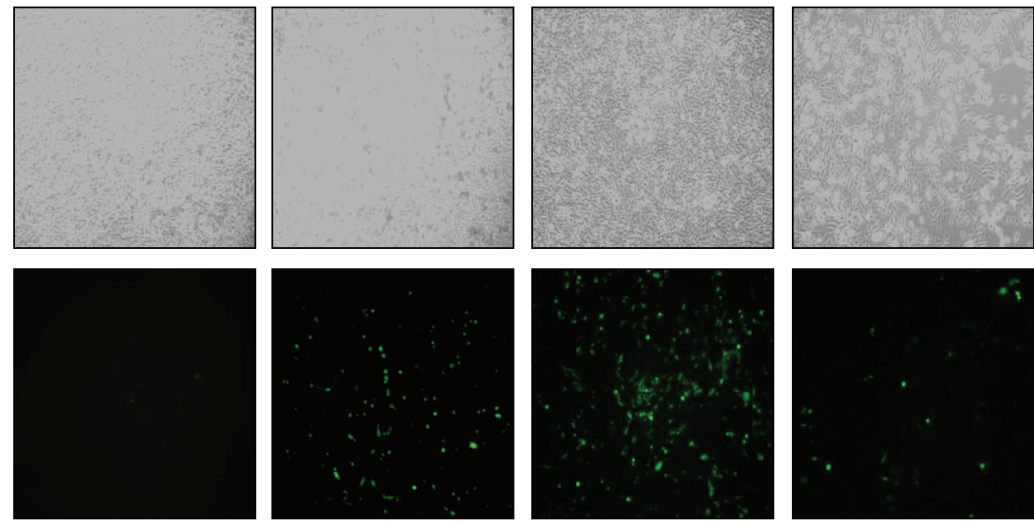

(b)
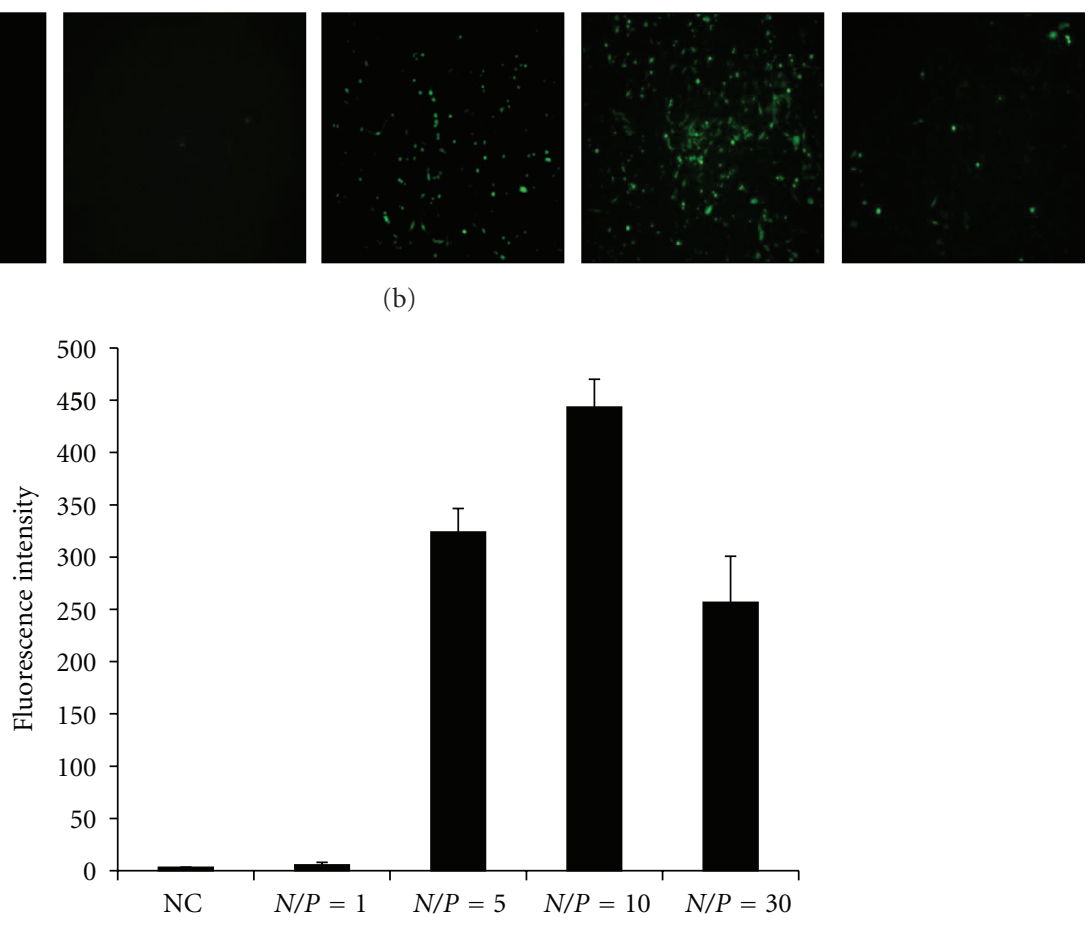

(c)

FIGURE 4: In vitro transfection efficiency of LPTC/DNA complexes. (a) Using $3 \mu \mathrm{g}$ of DNA and different dosages of LPTC, we formed each $N / P$ ratio in order from 1 to 30 . LPTC/DNA complexes were transfected into Balb/3T3 cells, and, $48 \mathrm{hr}$ later, the transfection efficiency was measured by flow cytometry. NC: cells alone. The data represent the mean \pm S.E. of six experiments. ${ }^{* *} P<0.01$ versus negative control. (b) Fluorescent microscopy of gene expression after in vitro transfection. Forty-eight hours after transfection, phase contrast and fluorescent microscopy images of transfectants were performed (200x magnification). (c) The gene expression after in vitro transfection. 


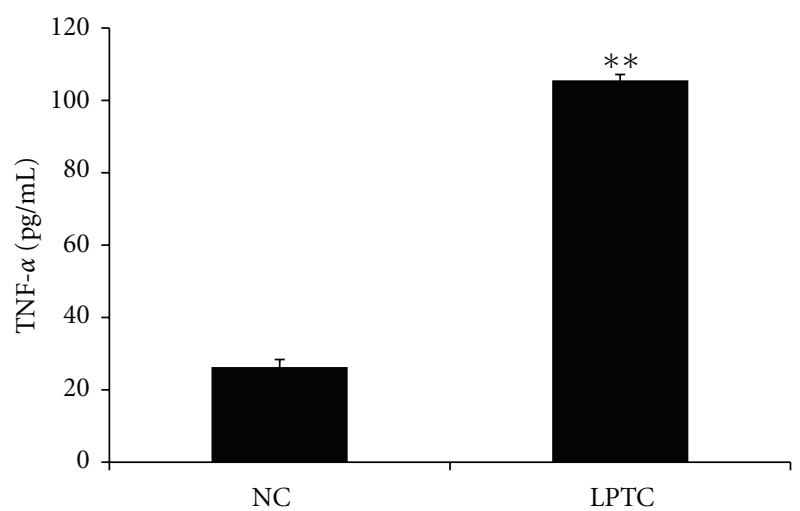

(a)
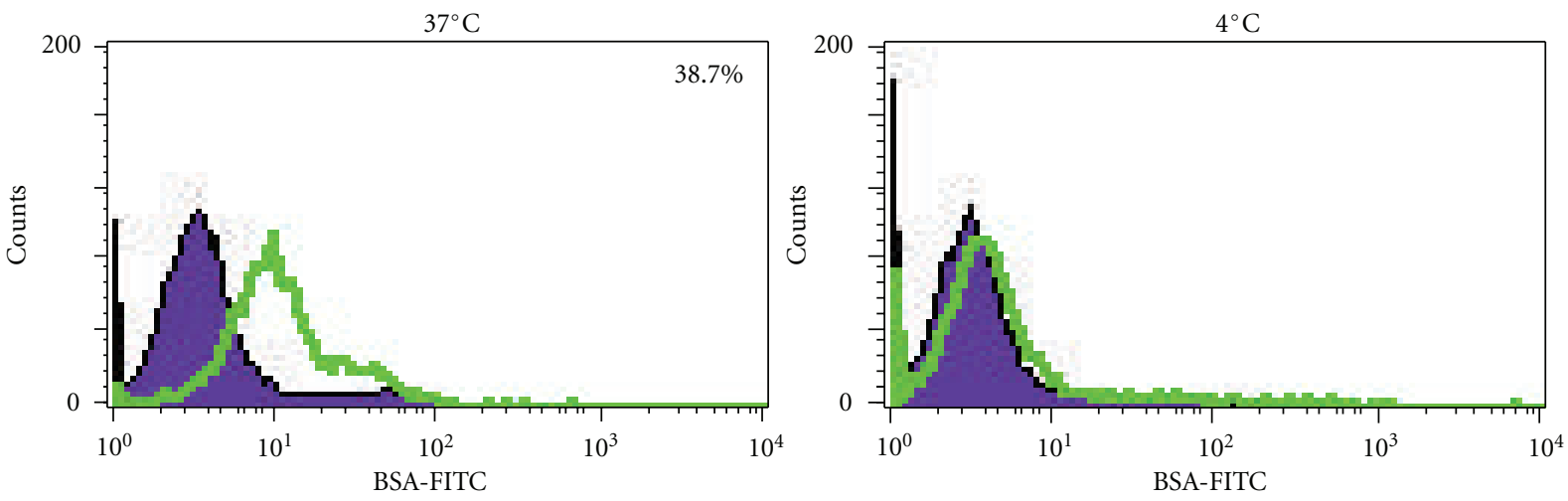

(b)

FIGURE 5: The immune responses of LPTCs. (a) Induction of TNF- $\alpha$ from naïve mice splenocytes stimulated with LPTC. The splenocytes of naïve mice $\left(4 \times 10^{6}\right.$ cells/well) were incubated with LPTC $(80 \mu \mathrm{g})$ in 24 well plates. After stimulation for $48 \mathrm{hr}$, the culture supernatant was collected, and the production of TNF- $\alpha$ was measured by ELISA. NC: cells alone. The data are expressed as means \pm SEM of three wells. ${ }^{* *} P<0.01$ versus negative control. (b) Cell uptake assay of LPTC/BSA-FITC complexes in P338/D1 cells. P338/D1 cells were cultured for 1 hr at $37^{\circ} \mathrm{C}$ or $4^{\circ} \mathrm{C}$ with $14 \mu \mathrm{g} / \mathrm{mL}$ BSA-FITC alone (dark side) or complexed with LPTC (grey line). Trypan blue was added to quench surfaceassociated BSA-FITC, and then the fluorescence intensity was measured by flow cytometry. BSA-FITC: bovine serum albumin-conjugated fluorescein isothiocyanate (FITC).

In addition, we investigated whether LPTCs could enhance cellular uptake. BSA-conjugated FITC was complexed with different dosages of LPTCs with macrophage cells (P338/D1). The intracellular fluorescence represented the degree of internalization. At $37^{\circ} \mathrm{C}$, the cellular uptake efficiency of LPTC/BSA-FITC complexes was increased by $38.7 \%$ compared with BSA-FITC alone (Figure 5(b) left panel). However, the cellular uptake efficiency of LPTC/BSAFITC complexes was the same as with BSA-FITC alone at $4^{\circ} \mathrm{C}$ (Figure 5(b) right panel).

3.6. The In Vivo Adjuvant Effects of LPTC on Heterologous Immunization. In vitro studies showed that LPTCs had efficacy in gene transfer and the cellular uptake of antigen by macrophage cells and stimulated the secretion of a proinflammatory cytokine (TNF- $\alpha$ ). Thus, we further investigated whether LPTC could be an effective vector to deliver DNA or antigen in vivo. First, to investigate the effect of LPTC on the induction of humoral response, a heterologous immunization protocol was developed by priming with DNA and boosting with protein antigen (Figure 6(a)). Then, the specific anti-Hphsp60 response was measured. The results showed that treatment with LPTC complexed with DNA or antigen anti-Hphsp60 Ig responses compared with immunization without LPTC (Figure 6(b)). Furthermore, LPTC complexed with $25 \mu \mathrm{g}$ of DNA increased anti-Hphsp60 Ig responses 2-fold higher compared with $12.5 \mu \mathrm{g}$ of DNA at week 4 (Figure 6(c)).

\subsection{The In Vivo Adjuvant Effect of LPTC on Codelivery Immu-} nization. Inducing an antigen-specific immune response in a short time is an important issue in clinical trials of vaccines. Here, a codelivery immunization protocol was developed that includes priming or boosting with DNA and protein antigens at the same time to investigate the effect of LPTCs on the induction of the humoral response (Figure 7(a)). Two weeks after the last boost, the results showed that the treatment with LPTCs complexed with DNA and protein antigen increased the anti-Hphsp60 Ig response by about 2fold (Figure 7(b)). 


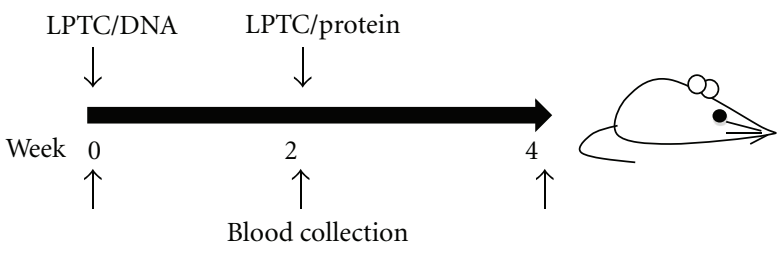

(a)

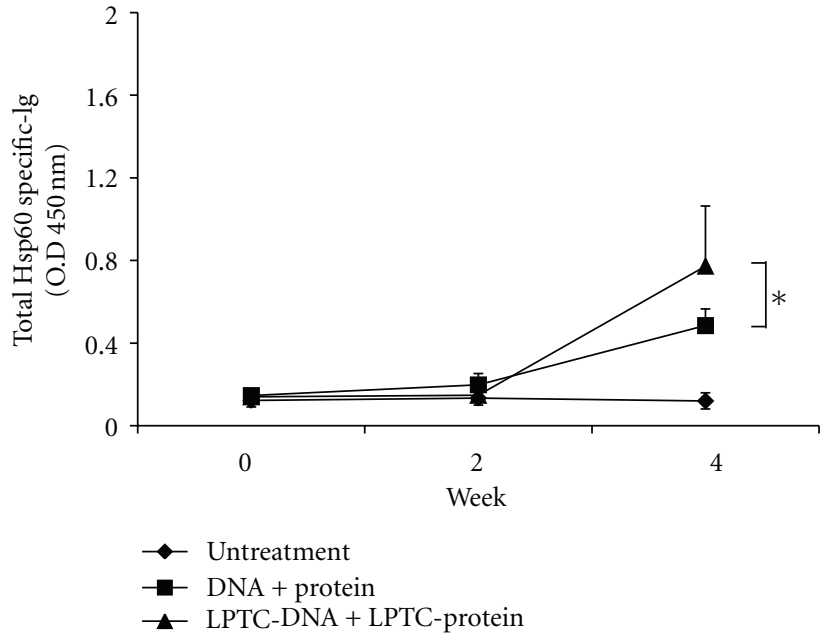

(b)

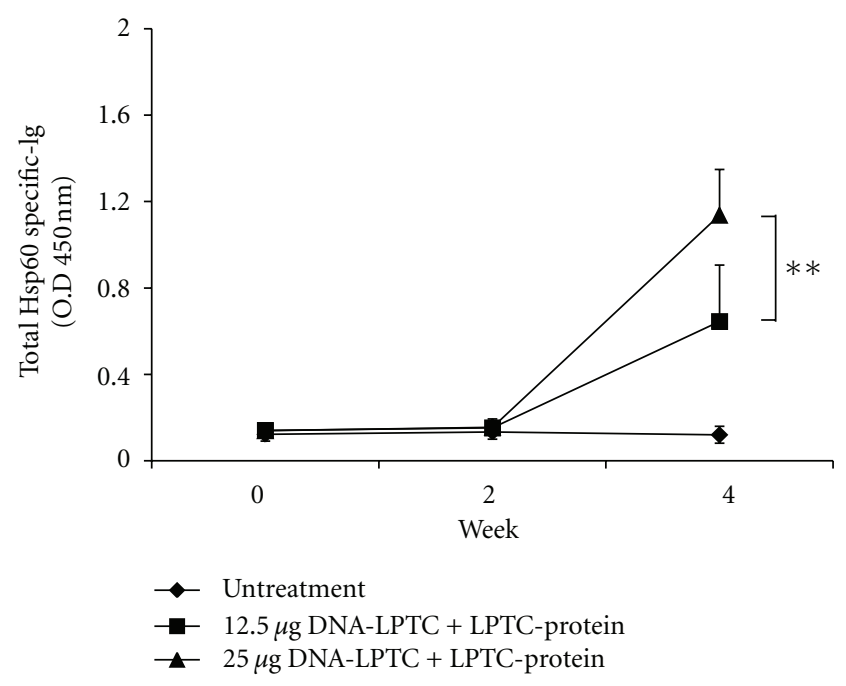

(c)

FIGURE 6: The adjuvant effects of the heterologous immunization regimen. (a) The heterologous vaccine protocol includes a prime boost schedule. Naïve mice were immunized by subcutaneous injection with one dose of DNA alone or the LPTC-DNA complex (12.5 $\mu$ g$25 \mu \mathrm{g} /$ dose $)$ followed by one dose of protein alone or the LPTC-protein complex (100 $\mu \mathrm{g} / \mathrm{dose})$ at weeks 0 and 2 , respectively. Ag-specific immune responses were measured at 0,2, and 4 weeks. (b) LPTC/DNA and LPTC/protein complexes induced hsp60-specific Ig responses by the heterologous immunization regimen. Three groups of female BALB/c mice were immunized by subcutaneous injection on week 0 with DNA alone $(12.5 \mu \mathrm{g} / 100 \mu \mathrm{L})$, LPTC-DNA complexes $(12.5 \mu \mathrm{g} / 100 \mu \mathrm{L})$ or LPTC-DNA complexes $(25 \mu \mathrm{g} / 100 \mu \mathrm{L})$ and then boosted on week 2 with protein alone $(100 \mu \mathrm{g} / 100 \mu \mathrm{L})$ or LPTC-protein complexes $(100 \mu \mathrm{g} / 100 \mu \mathrm{L})$. Serum was collected, and Hsp60-specific total Ig (IgG, IgM and IgA) responses were measured by Ag-specific ELISA. DNA: pCJ3-HpHsp60; protein: $\mathrm{rHpHsp60}{ }^{*} P<0.05$ versus DNA/protein group, ** $P<0.01$ versus $12.5 \mu$ g DNA-LPTC group.

\section{Discussion}

In recent years, the development of vaccines has mostly been focused on liposomes, which can encapsulate antigens within a lipid bilayer. The encapsulated antigens are slowly released from the vesicle to continuously stimulate host immunity, which can trigger more efficient immune responses than noncapsulated antigens. Cationic liposome-capsulated antigens can facilitate antigen uptake and presentation [5]. Furthermore, cationic liposomes have more potency than anionic or neutral liposomes in inducing cell-mediated immune responses to soluble proteins [4]. Various phospholipids have different adjuvant activities to induce protective immunity. These results suggest that the structures or components of liposomes may determine the strength of the immune responses or adjuvant effects.

Liposome-based vaccines have been investigated in human trials including vaccines against malaria, HIV, hepatitis $\mathrm{A}$, and influenza, and these vaccines were found to be safe and highly immunogenic [8]. However, liposome-based vaccines for animals are still rare. In livestock breeding, the prevention of infectious disease is very important for avoiding economic loss. Thus, developing an inexpensive and 


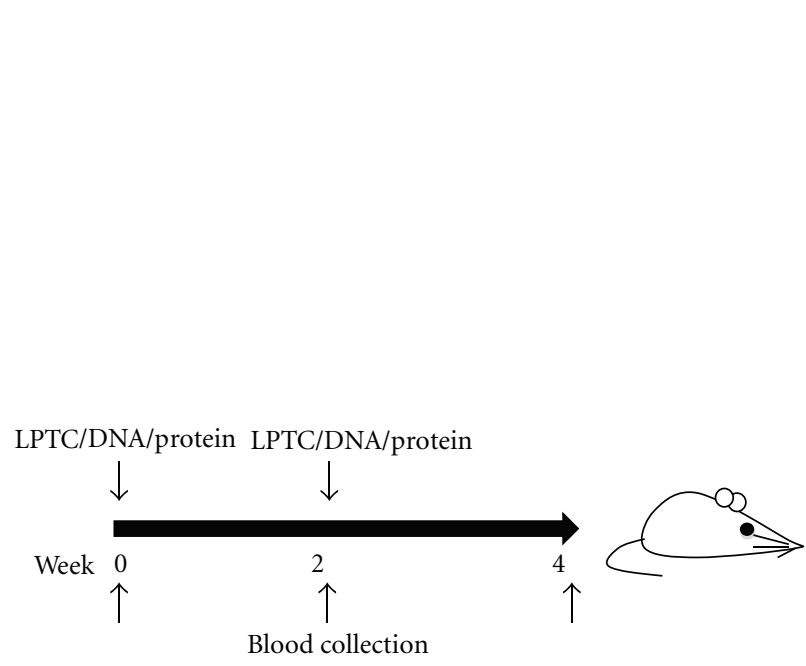

(a)

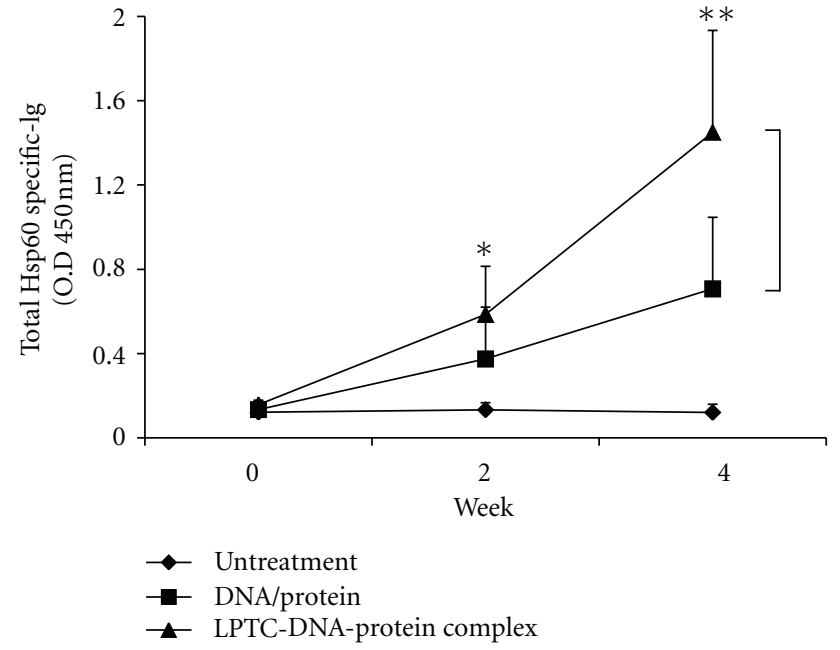

(b)

FIGURE 7: The adjuvant effects of the codelivery immunization regimen. (a) The codelivery vaccine protocol including the prime boost schedule. Naïve mice were immunized with two doses of DNA $(50 \mu \mathrm{g})$ and protein $(100 \mu \mathrm{g})$ or the codelivery of a LPTC-DNA $(50 \mu \mathrm{g})$ protein $(100 \mu \mathrm{g})$ complex at weeks 0 and 2 via subcutaneous injection. Ag-specific immune responses were measured at 0,2 , and 4 weeks. DNA was pCJ3-HpHsp60. Protein was $\mathrm{rHpHsp60.} \mathrm{(b)} \mathrm{LPTC/DNA} \mathrm{and} \mathrm{LPTC/protein} \mathrm{complexes} \mathrm{induce} \mathrm{hsp60-specific} \mathrm{Ig} \mathrm{responses} \mathrm{by} \mathrm{the}$ codelivery immunization regimen. Two groups of female BALB/c mice were immunized via subcutaneous injection. Serum was collected, and then total Hsp60-specific Ig responses were measured by Ag-specific ELISA. Negative control: untreated mice; DNA: pCJ3-hphsp60; protein: $\mathrm{rHpHsp60.}{ }^{* *} P<0.01$ versus DNA/Protein group.

efficient liposome-based animal vaccine is important for livestock farming [9]. Here, we developed novel liposomepolymer transfection complexes (LPTCs) with the high-molecular weight branched PEI and PEG and soybean oil. The cationic polymer PEI was an effective transfection reagent and had some advantages such as high cationic charge-density potential, which is able to compact DNA efficiently for enhanced delivery [10], and a "proton-sponge" effect, which allowed DNA release from the endosome to protect transgenes from degradation [11]. The other hydrophilic polymer molecule PEG has been used to coat liposomes, and the PEGcoated liposome may significantly diminish the liver and spleen uptake of macrophages, leading to increased blood circulation [12]. The third component is soybean oil, which is composed of three unsaturated fatty acids (linolenic acid, linoleic acid, and oleic acid) and two saturated fatty acids (stearic acid and palmitic acid). Here, soybean oil was used to form the liposome structure via sonication. Soybean oil may also allow the addition of immunostimulatory components such as the saponin adjuvant Quil A, which is derived from the bark of the South American Quillaja saponaria Molina tree and has been used as component of the immunostimulating complex (ISCOM) [13]. Immunostimulatory agents are typically hydrophobic in nature and have immunogenicity; thus, the addition of soybean oil through polar interactions improves the adjuvant effect of the vaccine. In addition, all of these components in LPTCs are very inexpensive, which reduces the cost of the animal vaccine for widespread inoculation that would prevent infectious diseases between animals.
Gene delivery vectors include cationic liposomes, cationic polymers, and polycationic liposomes, and they should be examined according to the following criteria: (1) DNA adsorptive ability, (2) the efficiency of gene delivery, (3) cytotoxicity, and (4) large-scale commercial manufacturing ability. These criteria are important for efficient gene expression and possible practical applications. Here, we constructed novel LPTCs that satisfied the above criteria and that had an efficient and rapid procedure for the production of the gene delivery vectors. LPTCs showed high positive charges, which absorbs DNA and forms smaller complexes. In addition, the complexes showed higher efficiency of gene transfer at $N / P$ ratios of 10 and 30 . Finally, we found that LPTCs had adjuvant effects and efficiently enhanced antigen-specific antibody responses in both immunization strategies (heterologous and codelivery).

LPTCs are round, nanometer in scale in size (Figures 1(a) and 1(b)), and positively charged. We speculated that the positive charge was due to the cationic polymer (PEI), and it may exist on the surface of particles in high-density hair-like filaments (Figure 1(a) right panel). According to the TEM images, the polymer layer consists of PEI and PEG on the surface of LPTC to form the cationic nanoparticle (Figure 1(a)). DNA and protein could be bound on the surface of LPTC via electrostatic interaction (Figure 1(c)). Polyethylenimine was an essential component to bind the proteins. We examined the dimension and surface charge changes that occurred with various $N / P$ ratios of LPTC/DNA (Figures 2(a) and 2(b)). The results showed that higher N/P ratios formed smaller complexes, and we hypothesized that DNA rigidly bound on LPTCs when the amount of LPTC 
was larger. This result also suggests that a high positive charge may reduce the aggregation by electronic repulsion, which encourages smaller LPTC/DNA complex formation. Furthermore, the positive charge can facilitate adherence to cellular membranes, inducing and increasing intracellular uptake.

A successful gene therapy or DNA vaccine relies on efficient DNA liberation from the endocytic vesicles and DNA nuclear localization for final gene expression. However, Lechardeur et al. proposed that cytosol nucleases are responsible for the rapid degradation of plasmid DNA, which limits DNA nuclear localization [14]. Our results showed that LPTC not only complexed with DNA efficiently at high $N / P$ ratios but also protected DNA from DNase I digestion (Figures 2(c) and 2(e)). Godbey et al. suggested that the protection of DNA by PEI resulted from a physical or electrostatic barrier to enzymatic degradation with DNAse I [15]. Thus, we speculate that PEI played an important role in LPTC-DNA complex formation and the protection from DNase I degradation.

Our in vitro transfection results showed that as the $N / P$ ratio increased, the transfection efficiency increased (Figure 4(a)). Expression could be easily visualized at N/P ratios of 5 and 10 (Figures $4(\mathrm{~b})$ and $4(\mathrm{c})$ ). However, the higher transfection efficiency at $N / P=30$ showed low expression by fluorescence microcopy (Figures 4(b) and 4(c)). A possible explanation for this result is that less DNA bound to LPTC when large amounts of LPTC were present, so less DNA entered into each cell. Nevertheless, large amounts of LPTC enhanced the entry of LPTC/DNA complexes into cells. We postulate that the N/P ratio of 10 , which showed the highest gene expression, was the most suitable charge ratio of the LPTC/DNA complex for DNA vaccine treatment in vivo.

Cationic lipids and cationic liposomes have been used as vaccine adjuvants in DNA vaccines and protein-based vaccines $[16,17]$. Thus, we investigated whether antigen adsorbed to cationic LPTC could effectively enhance the cellular uptake of antigen-presenting cells (APCs). We showed that LPTC enhanced the efficiency of cellular uptake (Figure 5(b)). We speculated that the cationic properties of LPTCs were good for targeting to the cell membrane of antigen-presenting cells, which subsequently leads to enhanced uptake. This hypothesis has been tested and confirmed to be the primary adjuvant mechanism of cationic liposomes by other studies [5].

A variety of DNA vaccine priming and recombinant viral boosting immunization strategies have been developed to enhance immune responses in humans. This prime and boost vaccination strategy has been used to overcome the ineffective induction of immune responses with DNA immunization alone in nonhuman primates and humans [12]. Furthermore, the advantages of this approach include a synergistic effect on the induction of immune responses and the generation of a robust $\mathrm{T}$-cell-mediated immune response [18]. Here, we used LPTC as a dual vector to carry DNA for priming immunization and carrying protein for boosting immunization and indeed observed a higher antigen-specific immune response. However, the animal vaccine strategy should consider how to induce higher immune responses in short times for a wide range of animals. Hence, we explored the possibility of efficiently codelivering a DNA vaccine and a protein-based vaccine by LPTC. The result showed that this vaccine strategy was successful for stimulating an immune response after single immunization and a higher immune response with two immunizations. Both of the immune responses showed higher antibody responses than a heterologous immunization strategy. Furthermore, the co-delivery vaccine strategy was also confirmed by other studies and has been shown to prime an enhanced and balanced specific immunity of Th1- and Th2-biased responses [19].

\section{Conclusions}

In this study, we confirmed the utility of LPTCs in in vitro and in vivo gene delivery and investigated the adjuvant effects of this compound. LPTCs showed potential for use in animal vaccines for farms that need large quantities of vaccine products with low cost, particularly for species where a large number of animals with a relatively low commercial value are utilized, such as chickens.

\section{Acknowledgment}

Y.-L. Lin and L.-Y. Chen contributed equally to this work.

\section{References}

[1] H. L. Davis and M. J. McCluskie, "DNA vaccines for viral diseases," Microbes and Infection, vol. 1, no. 1, pp. 7-21, 1999.

[2] J. Li, Y. Huang, X. Liang et al., "Plasmid DNA encoding antigens of infectious bursal disease viruses induce protective immune responses in chickens: factors influencing efficacy," Virus Research, vol. 98, no. 1, pp. 63-74, 2003.

[3] Y. L. Lin, Y. J. Lai, N. M. Tsai et al., "A new microsphere-based immunoassay for measuring the activity of transcription factors," Biological Procedures Online, vol. 12, no. 1, pp. 18-26, 2010.

[4] T. Nakanishi, J. Kunisawa, A. Hayashi et al., "Positively charged liposome functions as an efficient immunoadjuvant in inducing cell-mediated immune response to soluble proteins," Journal of Controlled Release, vol. 61, no. 1-2, pp. 233-240, 1999.

[5] K. Smith Korsholm, E. M. Agger, C. Foged et al., "The adjuvant mechanism of cationic dimethyldioctadecylammonium liposomes," Immunology, vol. 121, no. 2, pp. 216-226, 2007.

[6] H. H. Guan, W. Budzynski, R. R. Koganty et al., "Liposomal formulations of synthetic MUC1 peptides: effects of encapsulation versus surface display of peptides on immune responses," Bioconjugate Chemistry, vol. 9, no. 4, pp. 451-458, 1998.

[7] F. Brunel, A. Darbouret, and J. Ronco, "Cationic lipid DCChol induces an improved and balanced immunity able to overcome the unresponsiveness to the hepatitis B vaccine," Vaccine, vol. 17, no. 17, pp. 2192-2203, 1999.

[8] C. R. Alving, "Liposomal vaccines: clinical status and immunological presentation for humoral and cellular immunity," Annals of the New York Academy of Sciences, vol. 754, pp. 143152, 1995.

[9] J. P. Y. Scheerlinck and D. L. V. Greenwood, "Particulate delivery systems for animal vaccines," Methods, vol. 40, no. 1, pp. 118-124, 2006.

[10] M. Neu, D. Fischer, and T. Kissel, "Recent advances in rational gene transfer vector design based on poly(ethylene imine) and 
its derivatives," Journal of Gene Medicine, vol. 7, no. 8, pp. 992$1009,2005$.

[11] A. Akinc, M. Thomas, A. M. Klibanov, and R. Langer, "Exploring polyethylenimine-mediated DNA transfection and the proton sponge hypothesis," Journal of Gene Medicine, vol. 7, no. 5, pp. 657-663, 2005.

[12] D. Papahadjopoulos, T. M. Allen, A. Gabizon et al., "Sterically stabilized liposomes: improvements in pharmacokinetics and antitumor therapeutic efficacy," Proceedings of the National Academy of Sciences of the United States of America, vol. 88, no. 24, pp. 11460-11464, 1991.

[13] J. C. Cox, A. Sjölander, and I. G. Barr, "ISCOMs and other saponin based adjuvants," Advanced Drug Delivery Reviews, vol. 32, no. 3, pp. 247-271, 1998.

[14] D. Lechardeur, K. J. Sohn, M. Haardt et al., "Metabolic instability of plasmid DNA in the cytosol: a potential barrier to gene transfer," Gene Therapy, vol. 6, no. 4, pp. 482-497, 1999.

[15] W. T. Godbey, M. A. Barry, P. Saggau, K. K. Wu, and A. G. Mikos, "Poly(ethylenimine)-mediated transfection: a new paradigm for gene delivery," Journal of Biomedical Materials Research, vol. 51, no. 3, pp. 321-328, 2000.

[16] D. I. Bernstein, R. D. Cardin, F. J. Bravo et al., "Potent adjuvant activity of cationic liposome-DNA complexes for genital herpes vaccines," Clinical and Vaccine Immunology, vol. 16, no. 5, pp. 699-705, 2009.

[17] Y. Perrie, A. R. Mohammed, D. J. Kirby, S. E. McNeil, and V. W. Bramwell, "Vaccine adjuvant systems: enhancing the efficacy of sub-unit protein antigens," International Journal of Pharmaceutics, vol. 364, no. 2, pp. 272-280, 2008.

[18] M. M. Levine and M. B. Sztein, "Vaccine development strategies for improving immunization: the role of modern immunology," Nature Immunology, vol. 5, no. 5, pp. 460-464, 2004.

[19] M. Kwissa, E. B. Lindblad, R. Schirmbeck, and J. Reimann, "Codelivery of a DNA vaccine and a protein vaccine with aluminum phosphate stimulates a potent and multivalent immune response," Journal of Molecular Medicine, vol. 81, no. 8, pp. 502-510, 2003. 

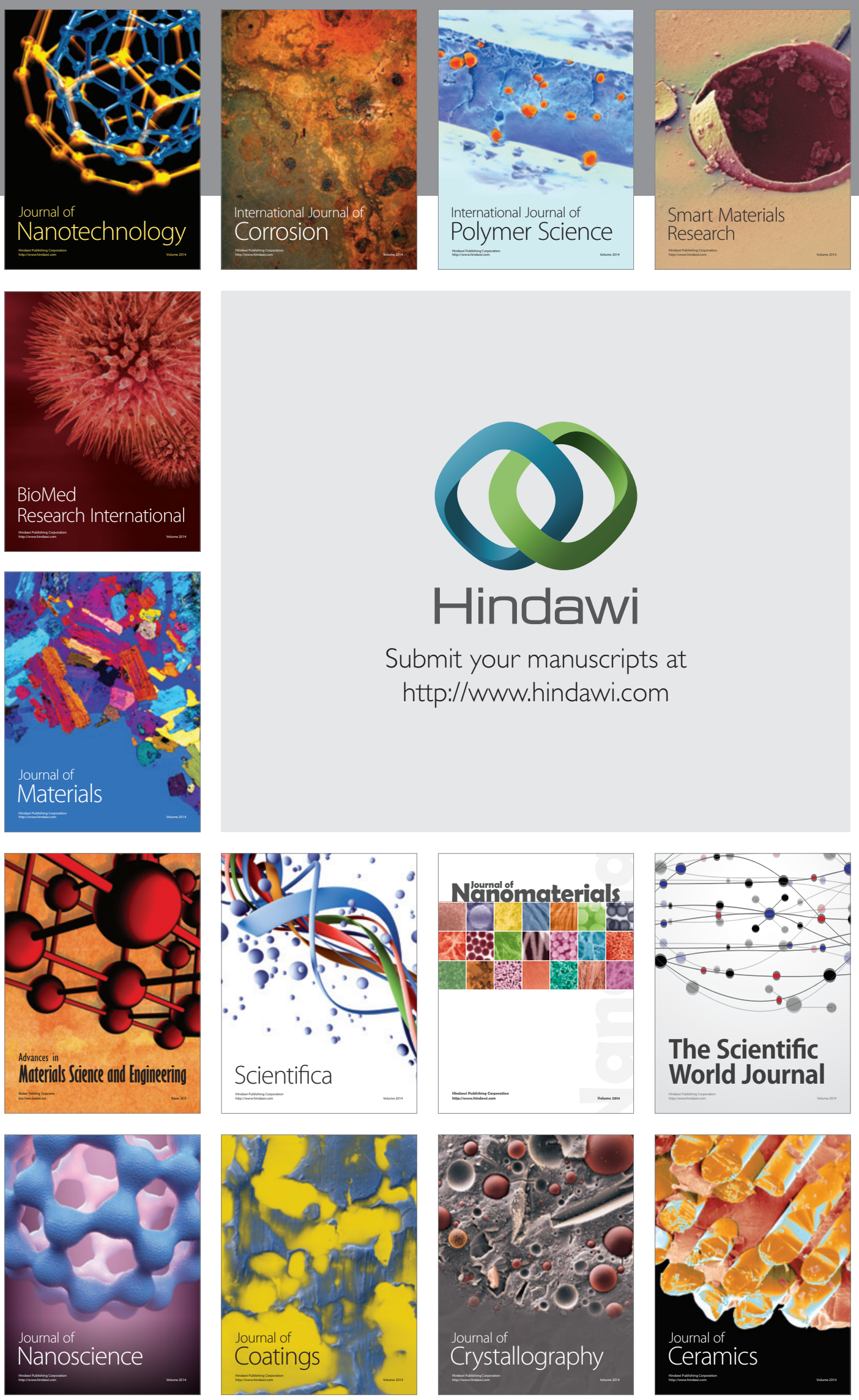

The Scientific World Journal

Submit your manuscripts at

http://www.hindawi.com

\section{World Journal}

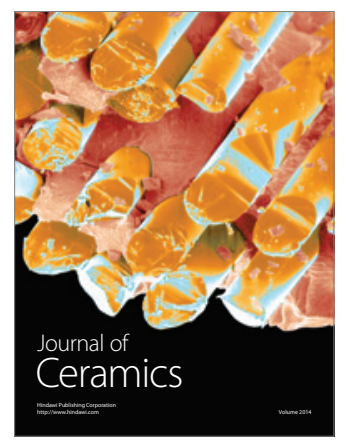

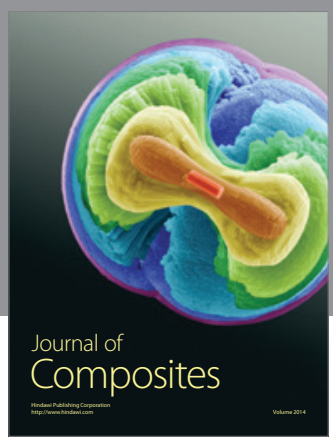
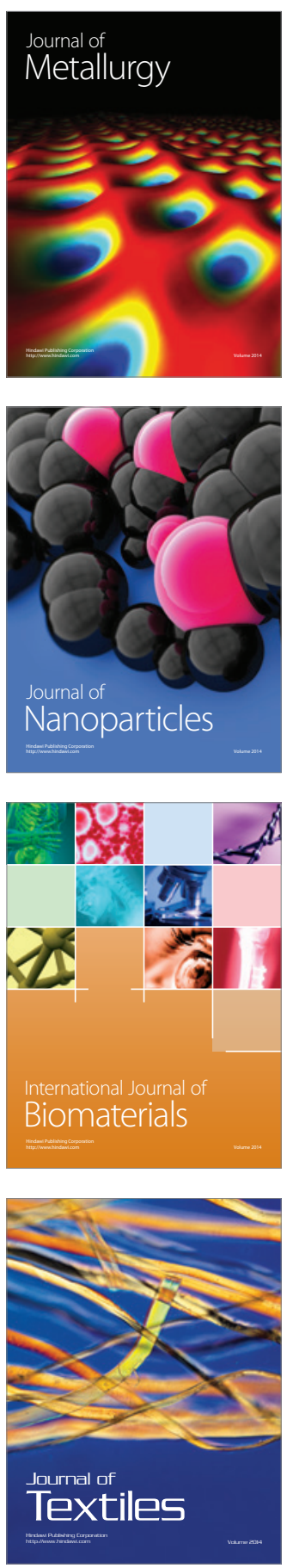